\title{
Propofol-Induced Hepatitis
}

\author{
Hanna Raisi ${ }^{1}$, Thomas Longerich² ${ }^{2}$, Bernardo Moreira Assuncao ${ }^{1}$, Sebastian Mueller ${ }^{1}$, Peter Schirmacher ${ }^{2}$, Helmut-Karl Seitz ${ }^{1}$ \\ ${ }^{1}$ Center for Alcohol Research (CAR), University of Heidelberg and Department of Medicine, Salem Medical Center, Heidelberg, Germany \\ ${ }^{2}$ Institute of Pathology, University Hospital Heidelberg, Heidelberg, Germany
}

\section{Doi: 10.12890/2020_001921 - European Journal of Case Reports in Internal Medicine - ㅇ EFIM 2020}

Received: 29/07/2020

Accepted: 03/09/2020

Published: 08/10/2020

How to cite this article: Raisi H, Longerich T, Moreira Assuncao B, Mueller S, Schirmacher P, Seitz HK. Propofol-induced hepatitis. EJCRIM 2020;7: doi:10.12890/2020 001921.

Conflicts of Interests: The Authors declare that there are no competing interests.

This article is licensed under a Commons Attribution Non-Commercial 4.0 License

\section{ABSTRACT}

Objectives: To present a rare case of propofol-induced hepatitis.

Materials and methods: A 59-year old man was referred to our department because of suspicion of toxic hepatitis after propofol anaesthesia for endoscopic colonoscopy.

Results: The patient had jaundice, increased transaminases demonstrating liver necrosis, and liver stiffness of $18 \mathrm{kPa}$. Liver biopsy revealed bridging necrosis and initial post-collapse fibrosis. Following therapy with steroids and $\mathrm{N}$-acetyl cysteine, the patient was discharged on the seventh day after admission in good general condition.

Conclusion: Although propofol is considered safe, it can cause acute hepatitis, the seventh published case of which is reported here. Importantly, treatment with $\mathrm{N}$-acetyl cysteine, a radical scavenger, but especially with steroids resulted in hepatic improvement.

\section{LEARNING POINTS}

- Drug-induced hepatitis is a severe illness caused by a large variety of agents, including many considered safe.

- It can occur in the absence of predisposing liver abnormality or disease.

- If the condition is correctly identified, clinical and laboratory abnormalities can be reversed with appropriate treatment.

\section{KEYWORDS}

Propofol, hepatitis, anaesthesia

\section{INTRODUCTION}

Most colonoscopies are performed under mild propofol anaesthesia. Here, we present a rare case of drug-induced acute hepatitis due to anaesthesia with propofol.

\section{CASE DESCRIPTION}

A 59-year-old man, who was $178 \mathrm{~cm}$ tall and weighed $76 \mathrm{~kg}$, was referred to the Department of Gastroenterology, Salem Medical Centre, Heidelberg, for toxic hepatitis. On admission, the patient had jaundice of the sclera and skin, light-coloured stool and dark urine for a few days, and complained of pain in his right upper abdomen, headache and dizziness.

The patient was in good general health with no history of hepatitis or jaundice, and had a negative disease history, except for uneventful surgery in 2011 for disc prolapse. He had not taken any medicines or herbal extracts in the last few months. He had no history of smoking. He reported occasional consumption of one to two bottles of beer per week. He had spent his holidays in Mauritius a few weeks before presentation to hospital, without any physical consequences such as fever or gastrointestinal abnormalities. One week before the present admission, colonoscopy had been performed under anaesthesia induced with propofol $200 \mathrm{mg}$. Three to four days after colonoscopy, the 
patient complained of nausea and pressure pain in his right upper abdomen, followed by the onset of jaundice shortly thereafter.

Table 1 shows the transaminase, bilirubin and alkaline phosphatase levels during the patient's hospital stay. Serum ferritin was 2,420 ng/ml. Ultrasound examination indicated hepatomegaly of $17.5 \mathrm{~cm}$ in the midaxillary line (MAL) associated with a high liver stiffness of $18.0 \mathrm{kPa}$ and a normal controlled attenuated parameter (CAP) of $185 \mathrm{~dB} / \mathrm{m}$ determined with transient elastography (Fibroscan, Echosens, Paris).

Laboratory tests for viral hepatitis A-E, Epstein-Barr virus and cytomegalovirus were negative. No auto-antibodies were detected. Late onset Wilsons's disease was excluded by a normal serum ceruloplasmin.

A liver biopsy was performed to determine the cause of hepatitis (Fig. 1). The biopsy showed a regular architecture with oedematous portal tracts containing a mild mixed inflammatory infiltrate with numerous macrophages and some eosinophils. There was neither interface hepatitis nor significant biliary damage, but bridging necrosis of the acinar parenchyma with marked bilirubin phagocytosis and initial postcollapse fibrosis was present, compatible with acute toxic hepatitis.

\begin{tabular}{|c|c|c|c|c|c|c|c|c|c|c|c|}
\hline & $-1 W$ & Adm & Day 1 & Day 3 & Day 5 & Day 7 & $2 W$ & $7 W$ & $9 \mathrm{~W}$ & $3 \mathrm{M}$ & Ref \\
\hline AST & 1,701 & 1,506 & 1,351 & 1,017 & 579 & 892 & 912 & 942 & 195 & 72 & $<50 \mathrm{U} / \mathrm{I}$ \\
\hline$A L T$ & 3,457 & 2,760 & 2,450 & 1,735 & 1,353 & 1,540 & 1,741 & 884 & 336 & 131 & $<50 \mathrm{U} / \mathrm{I}$ \\
\hline GGT & 448 & 233 & 200 & 155 & 221 & 371 & 613 & 385 & 222 & 87 & $<60 \mathrm{U} / \mathrm{I}$ \\
\hline$A P$ & & 198 & 179 & 154 & 165 & 184 & 164 & 207 & 117 & 70 & $40-130 \mathrm{U} / \mathrm{I}$ \\
\hline Bili & 12.0 & 26.7 & 26.3 & 24.2 & 22.3 & 20.3 & 16.8 & 10.8 & 2.9 & 1.1 & $<1.2 \mathrm{mg} / \mathrm{dl}$ \\
\hline INR & 1.01 & 1.16 & 1.17 & 1.16 & 1.08 & 1.01 & & 0.95 & & & $0.85-1.15$ \\
\hline Platelets & 239 & 295 & & 203 & & & & & & & $140-360 / \mathrm{nl}$ \\
\hline CRP & 2.7 & 4.67 & & & & & & & & & $<5.0 \mathrm{mg} / \mathrm{l}$ \\
\hline
\end{tabular}

Table 1. Laboratory values

Adm, admission; M, month; Ref, reference value; W, week
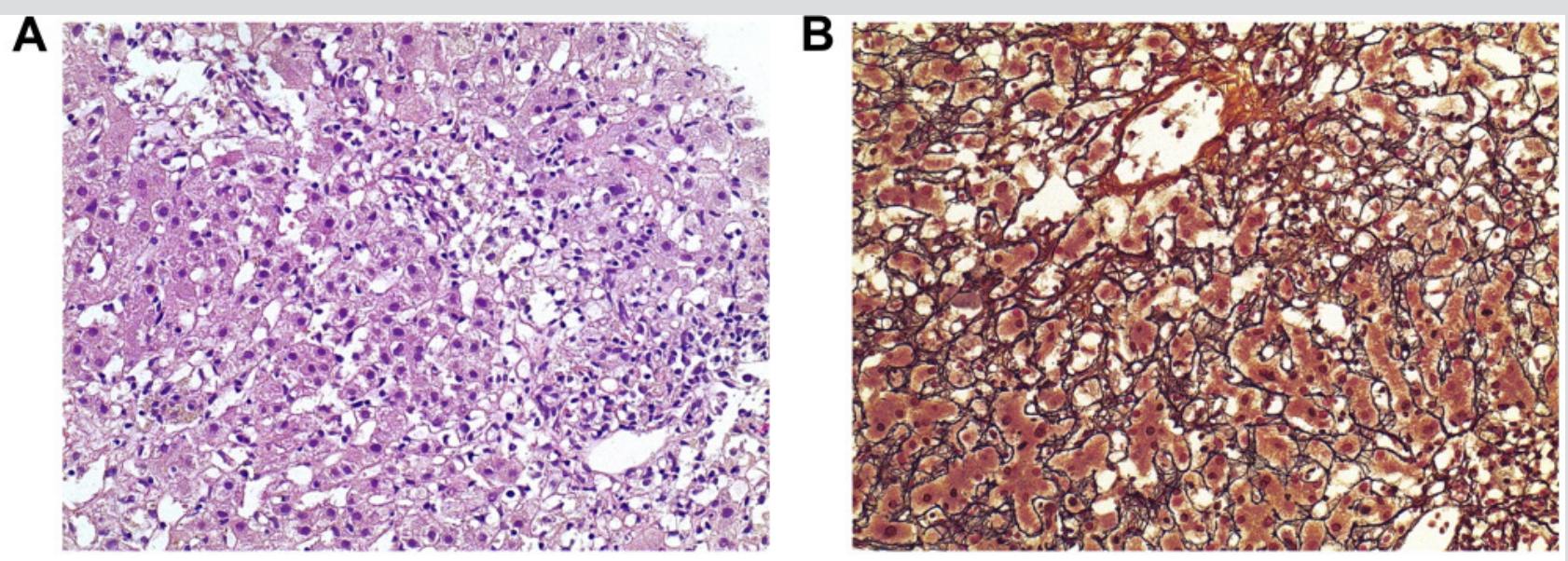

Figure 2. Coronary angiography in different angiographic views; view A and view B. In both views a dilated part of the middle segment of the left anterior descending (LAD) artery was seen (white arrows). LCx: Left circumflex artery; LM: left main coronary artery

Anamnestically, the only drug or toxin exposure within the last 3 weeks before admission to hospital was propofol during colonoscopy. Therefore, it is most likely that propofol was responsible for the acute hepatitis.

Although propofol is actually considered a less liver-toxic medication that can be used in patients with cirrhosis, a few cases of hepatotoxic damage caused by propofol have been reported ${ }^{[1-6]}$. In these cases, and also in our patient, propofol caused hepatocellular damage with signs of an immunoallergic mechanism (eosinophilic infiltrations). 
Empirical therapy with a N-acetyl cysteine (Fluimucil 20\%, $10 \mathrm{~g}$ in $500 \mathrm{ml} \mathrm{NaCl} 0.9 \%$ in $24 \mathrm{~h}$ ) was started on the day of admission. Serum transaminase activity and serum bilirubin dropped gradually under treatment (Table 2). The patient developed a rash on his upper chest on the third day of hospitalization. Blood tests showed increased IgE as a further sign of immunoreaction. Therefore, we added intravenous therapy with prednisolone $(250 \mathrm{mg}$ ).

Further laboratory results as well as clinical presentation confirmed gradual improvement. The patient was discharged on the seventh day after admission in good general condition under corticosteroid therapy with prednisolone $50 \mathrm{mg}$. He was referred for outpatient follow-up and treatment, with corticosteroid tapering suggested in 3-4 weeks.

\section{DISCUSSION}

We herein report a rare case of propofol-induced hepatitis, as only six other cases of propofol hepatic toxicity have been reported worldwide (Table 2) ${ }^{[1-6]}$. Propofol is considered safe and is widely used to induce anaesthesia in interventional procedures like endoscopy. In our case of acute hepatitis, no preconditions such as underlying liver disease or general allergic sensitivity were present to suggest increased risk for hepatic toxicity. Finally, it is noteworthy that treatment with steroids and N-acetyl cysteine was effective. Since serum transaminase activity improved only partially under therapy with $\mathrm{N}$-acetyl cysteine (a radical scavenger), and since the patient showed signs of an immune reaction, prednisolone was added. The fact that steroid therapy was effective demonstrates that propofol toxicity is primarily immunological in nature. Thus, a correct diagnosis with consecutive therapy can avoid progression to advanced liver disease.

\begin{tabular}{|c|c|c|c|c|c|}
\hline Year, Reference & Age & F/M & Location & Dose & Cause \\
\hline $2001[1]$ & 17 & $F$ & USA & $682 \mathrm{mg}$ & Femoral hernia surgery \\
\hline $2008[2]$ & 66 & M & Spain & - & ERCP \\
\hline $2009[3]$ & 62 & $F$ & USA & $250 \mathrm{mg}$ & Varicose surgery \\
\hline $2010[4]$ & 35 & $F$ & Germany & $540 \mathrm{mg}$ & Eye operation \\
\hline $2012[5]$ & 67 & $F$ & Spain & - & Japan \\
\hline $2013[6]$ & 75 & $F$ & mECT \\
\hline
\end{tabular}

Table 2. Cases of propofol intoxication described in the literature

\section{REFERENCES}

1. Anand K, Ramsay MA, Crippin JS. Hepatocellular injury following the administration of propofol. Anesthesiology 2001;95(6):1523-1524.

2. Polo-Romero FJ, Paricio P, Tovar A, Alonso JM. Propofol-induced acute toxic hepatitis after brief sedation for endoscopic retrograde cholangiopancreatography. Endoscopy 2008;40(Suppl 2):E49.

3. Nguyen HD, Borum ML. Acute hepatitis in a patient given propofol during colonoscopy. South Med J 2009;102(3):333-334.

4. Kneiseler G, Bachmann HS, Bechmann LP, Dechene A, Heyer T, Baba H, et al. A rare case of propofol-induced acute liver failure and literature review. Case Rep Gastroenterol 2010;4(1):57-65.

5. Rocha-Honor E, Polo-Romero FJ, Sánchez-Beteta P, Martínez-Peguero J, Santisteban-López Y, Beato-Pérez JL. Acarbosa y propofol: ¿una peligrosa combinación? Rev Esp Anestesiol Reanim 2014;61(2):109-111.

6. Asai A, Yagi M, Tsuchimoto Y, Fukunishi S, Takeshita A, Tsuda Y, et al. A rare case of propofol-induced liver injury during modified electroconvulsive therapy in an elderly woman. Intern Med 2013;52(7):761-765. 